\title{
A Numerical Experiment of Medium-Scale Disturbances: Dry Model
}

\author{
By Tatsushi Tokioka \\ Meteorological Research Institute, Tokyo \\ (Manuscript received 9 March 1972, in revised form 16 May, 1972)
}

\begin{abstract}
Numerical experiments concerning the medium-scale disturbances were performed with use of a dry model in a channel flow and three typical patterns of disturbances were obtained. When the initial Richardson number $(R i)$ of the basic field was about 2.0, ordinary baroclinic waves* developed. When $R i$ was about 0.4 initially, symmetric type of disturbances grew. While, when there existed statically unstable domain initially, a different type of organized disturbances developed. The pattern of the surface pressure resembles the pattern of Case $\mathbf{B}$ presented by the numerical experiment of Gambo $(1970 \mathrm{~b})$. Convective redistribution of heat at small $R i$ atmosphere played an essential role in the development of this wave.
\end{abstract}

\section{Introduction}

In the middle and high latitude regions, there appear cyclone waves with the horizontal scale of about several thousand kilometers. Besides them, medium-scale disturbances with the scale of about $1 \sim 2$ thousand kilometers also exist. The development of medium-scale cyclones is often observed around Japan, especially over the eastChina sea or in the neighbourhood of Nansei Islands (Ryukyu Islands) area.

Recently, studies concerning medium-scale phenomena have been made extensively with different approaches, and knowledges about them have increased. One approach to the phenomena is synoptic studies. Matsumoto, Yoshizumi and Takeuchi (1970) analyzed medium-scale disturbances observed in the "Baiu front". They showed that the disturbances are accompanied with the heavy rainfall and that they had indirect sense of circulation in the lower levels. They also studied characteristics of zonally averaged fields and reported the existence of super-geostrophic low-level jet seream. Matsumoto, Ninomiya and Yoshizumi (1971) extended the analysis and noted that a mid-tropospheric warm and moist belt may be due to the intense convective activity. They also estimated the Richardson number and

* In this paper the term "ordinary baroclinic waves" will be used to refer to baroclinic unstable waves of Eady's type (1949). obtained the value 1 to 5 for the layer between 900 and $600 \mathrm{mb}$.

On the other hand, characteristic features of the small $R i$ atmosphere have been studied by Stone $(1966,1970)$ and Tokioka $(1970,1971)$ as a stability problem. Stone (1966) studied a nongeostrophic stability properties of baroclinic fluids for several limiting cases and obtained a growth rate peak of symmetric instability at $k$ (wavenumber in the east-west direction) $=0$ and $l$ (wavenumber in the north-south direction) $=\infty$ when $R i<1$. Stone (1970) and Tokioka (1970, 1971) further studied details of the characteristics of the model. The former laied his emphasis on the position of the maximum growth rate in the wavenumber domain and its change with $R i$, whereas the latter paid his attention to structural and energetical properties of unstable waves as well as the growth rate behaviour. The main results of these theoretical studies are summarized as follows:

i) When $R i>1.0$, there is a growth rate peak of ordinary baroclinic waves at a finite $k$ when $l=0$.

ii) When $R i<1.0$, there appears another unstable mode (symmetric instability), the maximum growth rate of which exists at $k=0$ and $|l|=\infty$. In the range $1.0>R i>$ 0.95 , the baroclinic mode is more unstable, while symmetric mode becomes more unstable when $0.95>R i$. 
Table 1. Specification of numerical experiments

\begin{tabular}{|c|c|c|c|c|}
\hline Case** & Initial State & $\begin{array}{c}\text { Initial } \\
\text { Disturbance }\end{array}$ & Resolution & $\begin{array}{l}\text { Type of Developed } \\
\text { Disturbance }\end{array}$ \\
\hline NJ 2 A & $\begin{array}{l}\left.\begin{array}{l}\mathrm{T}=\mathrm{T}_{\mathrm{M}} \\
\mathrm{u}=\mathrm{U}_{1}\end{array}\right\} \text { at } \mathrm{y}=\mathrm{Y}_{\mathrm{o}} / 2 \\
\text { exactly no jet, } \\
\mathrm{Ri} \sim 2\end{array}$ & A & $\begin{array}{l}15 \times 15 \times 13 \\
\Delta \mathrm{x}=\Delta \mathrm{y}=80 \mathrm{~km} \\
\Delta \mathrm{t}=1.5 \mathrm{~min}\end{array}$ & $\begin{array}{l}\text { baroclinic unstable } \\
\text { waves }\end{array}$ \\
\hline $\mathrm{NJ} 4 / 5 \mathrm{~A}$ & 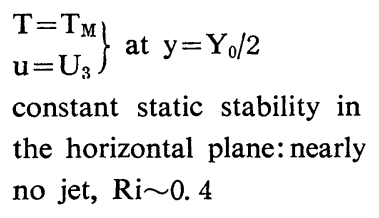 & A & $\begin{array}{l}15 \times 15 \times 9 \\
\Delta \mathrm{p}=90 \mathrm{mb} \\
\Delta \mathrm{x}=\Delta \mathrm{y}=80 \mathrm{~km} \\
\Delta \mathrm{t}=1.5 \mathrm{~min}\end{array}$ & $\begin{array}{l}\text { symmetric type } \\
\text { disturbance }\end{array}$ \\
\hline NJ $1 / 2 \mathrm{~A}$ & $\begin{array}{l}\left.\begin{array}{l}\mathrm{T}=\mathrm{T}_{\mathrm{M}} \\
\mathrm{u}=\mathrm{U}_{2}\end{array}\right\} \text { at } \mathrm{y}=\mathrm{Y}_{0} / 2 \\
\text { exactly no jet, statically } \\
\text { unstable region exists }\end{array}$ & A & $\begin{array}{l}15 \times 15 \times 13 \\
\Delta \mathrm{p}=70 \mathrm{mb} \\
\Delta \mathrm{x}=\Delta \mathrm{y}=80 \mathrm{~km} \\
\Delta \mathrm{t}=1.5 \mathrm{~min}\end{array}$ & $\begin{array}{l}\text { frontal wave type* } \\
\text { (after stabilization } \\
\text { symmetric type wave) }\end{array}$ \\
\hline NJ $1 / 2 \mathrm{~B}$ & same as Case $\mathrm{NJ} 1 / 2 \mathrm{~A}$ & B & $\begin{array}{l}15 \times 15 \times 13 \\
\Delta \mathrm{p}=70 \mathrm{mb} \\
\Delta \mathrm{x}=\Delta \mathrm{y}=80 \mathrm{~km} \\
\Delta \mathrm{t}=1.5 \mathrm{~min}\end{array}$ & $\begin{array}{l}\text { similar to } \\
\text { that of case } \mathrm{NJ} 1 / 2 \mathrm{~A}\end{array}$ \\
\hline $\mathrm{J} 1 / 2 \mathrm{~A}$ & $\begin{array}{l}T=T_{M} \text { at } y=Y_{0} / 2 \\
u=U_{2} \sin \left(\pi y / Y_{0}\right) \\
\text { statically unstable region } \\
\text { exists }\end{array}$ & $\mathrm{A}$ & $\begin{array}{l}15 \times 15 \times 13 \\
\Delta \mathrm{p}=70 \mathrm{mb} \\
\Delta \mathrm{x}=\Delta \mathrm{y}=80 \mathrm{~km} \\
\Delta \mathrm{t}=1.5 \mathrm{~min}\end{array}$ & $\begin{array}{l}\text { similar to } \\
\text { that of case } \mathrm{NJ} 1 / 2 \mathrm{~A}\end{array}$ \\
\hline
\end{tabular}

* This term is used only to denote a disturbance which has a finite and narrow preferred scale in the meridional direction.

** A name of each case is composed of three parts. First part, "J" or "NJ", indicates that the initial horizontal wind is of jet profile or of no jet profile respectively. Second part is a representative value of the Richardson number at a final stage of the integration, and the third part denotes the type of initial disturbances described in Section 2.2.

From these studies, it was made clear that the horizontal scale of the most unstable baroclinic wave becomes about $1,000 \mathrm{~km}$ or so when $\mathrm{Ri}$ is of the order of unity, and that a maximum growth rate cannot be obtained with a finite preferred scale in the meridional direction. As for the former point, Gambo (1976a) obtained the same result from a scale consideration.

Numerical experiments of medium-scale disturbances have been made by Gambo $(1970 \mathrm{~b})$ in a channel flow and two typical patterns of disturbances corresponding to different initial conditions were shown: one type corresponds to ordinary baroclinic waves, while the other has quite a different surface pressure pattern. He attributed the appearance of the latter disturbance to the smallness of effective $R i$.
The present paper aims to study the characteristic feature of medium-scale disturbances, especially of their structure and energetics, from numerical experiments. Throughout the computation the cause on the generation of the disturbances will be discussed from the dynamical point of view.

\section{Model and numerical scheme}

\section{1. Model}

We will treat a channel flow and use primitive equations in pressure coordinate system. The equations are written as follows;

$$
\frac{d u}{d t}-f v=-\frac{\partial \phi}{\partial x}
$$




$$
\begin{gathered}
\frac{d v}{d t}+f u=-\frac{\partial \phi}{\partial y}, \\
\alpha=-\frac{\partial \phi}{\partial p}, \\
\frac{\partial T}{\partial t}-\frac{\alpha \omega}{C_{p}}=\frac{1}{C_{p}} \dot{Q}, \\
\frac{\partial u}{\partial x}+\frac{\partial v}{\partial y}+\frac{\partial \omega}{\partial p}=0, \\
\frac{d}{d t}=\frac{\partial}{\partial t}+u \frac{\partial}{\partial x}+v \frac{\partial}{\partial y}+\omega \frac{\partial}{\partial p},
\end{gathered}
$$

where the following notations are used;

$(u, v)$ : velocity components in the eastward $(x)$ and northward $(y)$ diretions respectively

$\omega: \mathrm{dp} / \mathrm{dt}$

$f$ : Coriolis parameter

$\phi$ : geopotential

$T$ : temperature

$\dot{Q}$ : rate of heating due to dry convective adjustment

$\alpha$ : specific volume

$C_{p}$ : specific heat of air at constant pressure

We use a cyclic boundary condition at $x=0$ and $x=X_{0}$. At the south $(y=0)$ and north $\left(y=Y_{0}\right)$ boundaries, $u, \omega, \phi$ and $T$ are assumed to be symmetric with respect to the boundaries, while $v$ is assumed to be antisymmetric with respect to them. $X_{0}$ and $Y_{0}$ are set equal to $1,120 \mathrm{~km}$. This value is determined so as to coincide with the preferred scale obtained from the linear stability study (Tokioka, 1971). As the preferred scale in the east-west direction is about $1,100 \mathrm{~km}$ and does not differ so much with the change of $R i$ when $R i$ is of the order of unity, $X_{0}$ is fixed to $1,120 \mathrm{~km}$ throughout all cases.

Equations (2.1) through (2.5) are transformed into the finite difference form devised by Okamura (personal communication). This scheme conserves the momentum and energy. The atmosphere is divided into 13 layers in the vertical. i.e., $\Delta p=70 \mathrm{mb}$ except the case $\mathrm{NJ} 4 / 5 \mathrm{~A}$, where 9 layer model was used $(\Delta p=90 \mathrm{mb})$. Upper boundary condition is applied at $p=100 \mathrm{mb}$ for the 13 layer model and at $200 \mathrm{mb}$ for the 9 layer model (see Table 1). The horizontal grid size is set equal to $80 \mathrm{~km}$ in all cases. The method of dry convective adjustment is similar to that presented by Manabe et. al (1965). As for the time integration, the Eular backward scheme

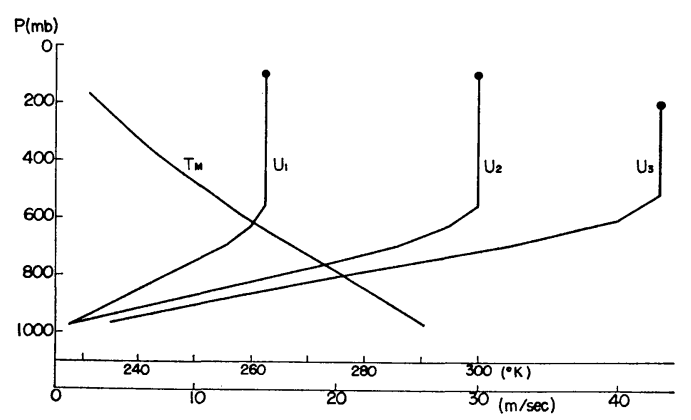

Fig. 1. Vertical distribution of temperature and zonal velocity used as initial conditions.

(Matsuno, 1966) is used. The time increment is set equal to $1.5 \mathrm{~min}$ throughout the computation.

\subsection{Initial field}

Initial field was given so as to satisfy the thermal wind balance. Five cases were treated (see Table 1). Initial temperature profile at $y=$ $Y_{0} / 2$ is shown in Fig. 1. Note that this temperature field, although rather unrealistic, gives low static stability in the dry model. This profile was used in all cases. Vertical profiles of zonal velocity at $y=Y_{0 / 2}$ are also shown in Fig. 1.

In Case NJ $2 \mathrm{~A}$, the profile $U_{1}$ without horizontal wind shear was used. From the distribution of zonal velocity in the whole domain and temperature profile at $y=Y_{0} / 2$ we can evaluate temperature field with use of the thermal wind relation. In pressure coordinate system, temperature field thus obtained does not assure constant static stability, but varies in the $y$-direction. The averaged $R i$ in the lower half of the meridional section was about 2.0 ranging from 0.1 to 5.0 .

In Case $\mathrm{NJ} 1 / 2 \mathrm{~A}$, zonal velocity was increased to twice the value of $\mathrm{NJ} 2 \mathrm{~A}$ (profile $U_{2}$ in Fig. 1). Horizontal wind shear was not considered. In this case, initial field included statically unstable region in about one third domain from the southern boundary. Although ' statically unstable regions will be limited in small portions in nature even if they exist, the presence of statically unstable domain in the present dry model will represent a role of heat redistribution.

Initial basic field of Case $\mathrm{NJ} 1 / 2 \mathrm{~B}$ was the same as that of Case $\mathrm{NJ} 1 / 2 \mathrm{~A}$. In Case $\mathrm{J} 1 / 2 \mathrm{~A}$, sine profiled jet $U_{2} \sin \left(\pi y / Y_{0}\right)$ was used. In this case, there also existed statically unstable region in a small limited area. 
In Case NJ 4/5 A, temperature filed was determined at first so that the static stability is constant in the horizontal plane. Zonal velocity was then calculated to satisfy the thermal wind relation from the temperature field. As the temperature gradient in the meridional direction at the surface was not given exactly constant, zonal velocity varied slightly in the horizontal plane. The vertical profile at $y=Y_{0} / 2$ is shown in Fig. 1 by the curve $U_{3}$. The Richardson number was nearly equal to 0.4 in the lower half of the atmosphere.

To these balanced fields, small disturbances were added in the geopotential field initially. The following two types were used as initial disturbances.

Type A: $\phi^{\prime}=\sin \left(\pi y / Y_{0}\right) \sin \left(2 \pi x / X_{0}\right) F(p)$

Type B: $\phi^{\prime}=\sin \left(2 \pi y / Y_{0}\right) \sin \left(2 \pi x / X_{0}\right) F(p)$

where $F(p)$ is the amplitude, the maximum of which was 2 g.p.m.. Types of the initial disturbances used in the experiments are also listed in Table 1. Disturbances in the temperature and horizontal wind fields were calculated by use of the hydrostatic and geostrophic relations from the geopotential field.

\section{Results of numerical experiment}

\subsection{Growth of disturbances}

Each physical quantity $S$ was divided into the zonally averaged part $\bar{S}$ and the deviation from it $S^{\prime}$, i.e., $S=\bar{S}+S^{\prime}$. Then kinetic energy of disturbance was defined by $\overline{\bar{K}} e \stackrel{X, Y, P}{=} \frac{1}{2}\left({\overline{\overline{u^{\prime 2}}}}^{X, Y, P}+\right.$ \left.${\overline{v^{\prime}}}^{-X, Y, P}\right)$, where $=X, Y, P$ indicates an integration over $x, y$ and $p$. Fig. 2 shows the time change of $\overline{\overline{K e}}^{X, Y, P}$. The growth rates are nearly equal to $12 \mathrm{hrs}$ in the $e$-folding time except Case NJ $2 \mathrm{~A}$. Among them, however, the growth rates of $\mathrm{NJ} 1 / 2 \mathrm{~A}$ and $\mathrm{NJ} 1 / 2 \mathrm{~B}$ are the largest. There are little differences in the growth rate between the two. In the linear stability analysis, on the other hand, smaller scale of disturbances in the meridional direction is preferred when $R i$ is less than 0.95. This discrepancy may be due to the poor horizontal resolution and to the existence of statically unstable region. Dry convective adjustment in that region may possibly have changed the growth rate behaviour.
The growth rate of $\mathrm{J} 1 / 2 \mathrm{~A}$ is a little less than that of NJ $1 / 2 \mathrm{~A}$. This is due to the weak zonal velocity near both the lateral boundaries where the growth of the disturbances is suppressed. The growth rate of $\mathrm{NJ} 2 \mathrm{~A}$ is small compared to other four cases. This is consistent with the large $R i$ compared to other cases. The e-folding. time is about $25 \mathrm{hrs}$.

There are three main energy sources to $\overline{\bar{K}}^{X, Y, P}$,

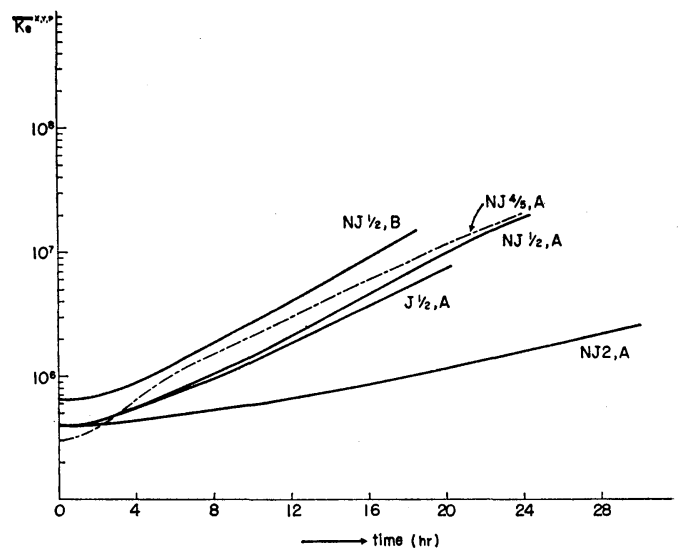

Fig. 2. Time change of kinetic energy of disturbance $\overline{\bar{K} e^{X}}, Y, P$ (in unit $\mathrm{km}^{4} \mathrm{mb} / \min ^{2}$ ).

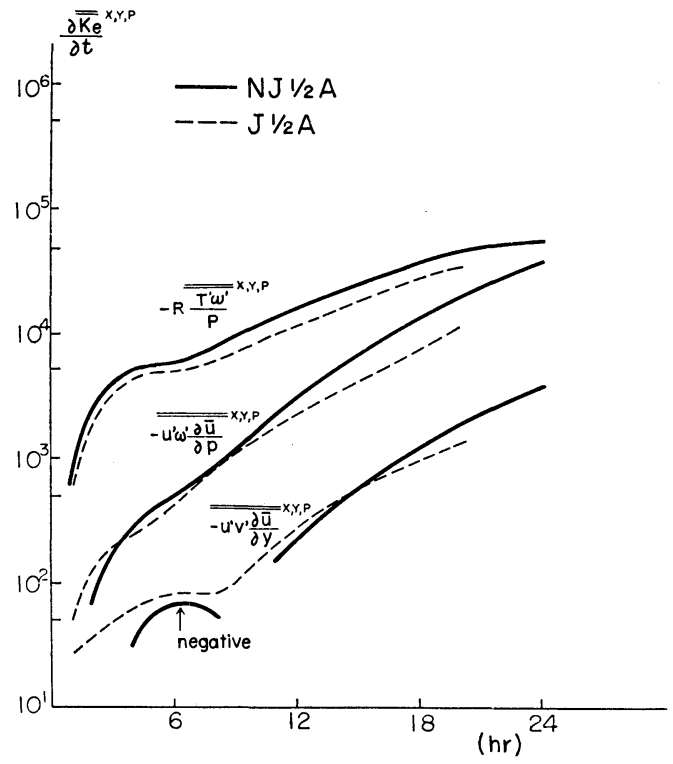

Fig. 3. Time change of dominant energy conversion terms to $\overline{\overline{K e}} \bar{X}, Y, P$ for Case NJ 1/2 A and Case J1/2 A (in unit $\mathrm{km}^{4} \mathrm{mb} / \mathrm{min}^{3}$ ). 


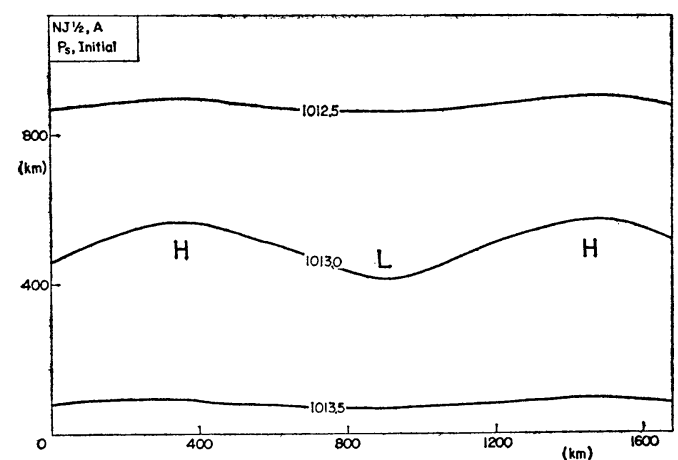

Fig. 4. Initial surface pressure pattern for Case NJ 1/2 A. In other cases except $\mathrm{NJ} 1 / 2 \mathrm{~B}$, initial patterns are similar to this figure.

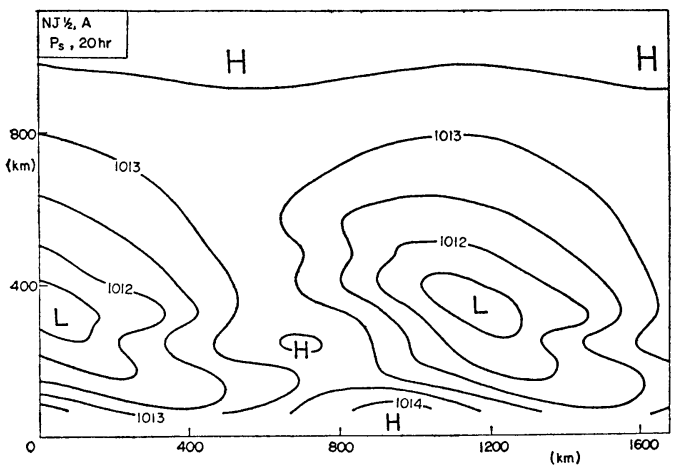

Fig. 5. Surface pressure pattern for Case NJ $1 / 2 \mathrm{~A}$ at $20 \mathrm{hrs}$.

i.e., energy conversion from potential energy $-R \frac{{\overline{T^{\prime} \omega^{\prime}}}^{X}, Y, P}{P}$, energy conversion from zonal kinetic energy through the vertical wind shear $-{\overline{u^{\prime} \omega^{\prime} \frac{\partial \bar{u}}{\partial p}}}^{X, Y, P}$, and energy conversion from zonal kinetic energy through the horizontal wind shear $-{\overline{u^{\prime} v^{\prime} \frac{\partial \bar{u}}{\partial y}}}^{X, Y, P}$. Fig. 3 shows the time change of these main terms in Case $\mathrm{NJ} 1 / 2 \mathrm{~A}$ and Case $\mathrm{J} 1 / 2 \mathrm{~A}$, Energy conversion from potential energy is dominant in every stage, but relatively large contribution of $-\overline{u^{\prime} v^{\prime} \frac{\partial \bar{u}}{\partial p}}$ is notable. This is consistent with the fact that $R i$ is small. It should be noted that no appreciable differences in $-{\overline{u^{\prime} v^{\prime}}}^{\frac{\partial \bar{u}}{\partial y}}{ }^{,, Y, P}$ exist between the two cases after $10 \mathrm{hrs}$ and that the contribution of

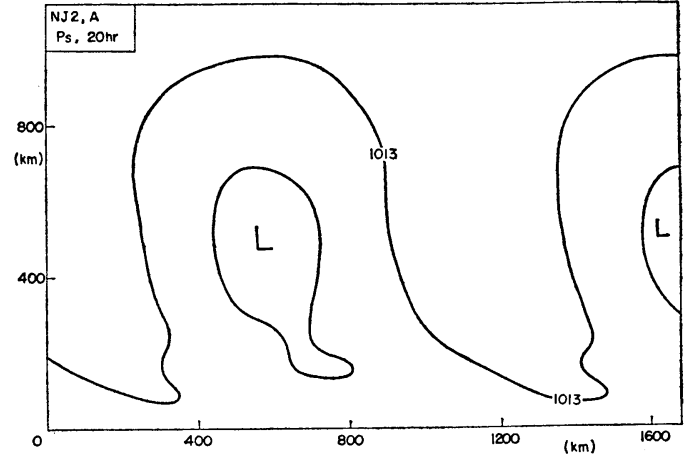

Fig. 6. Surface pressure pattern for Case NJ2A at $20 \mathrm{hrs}$.

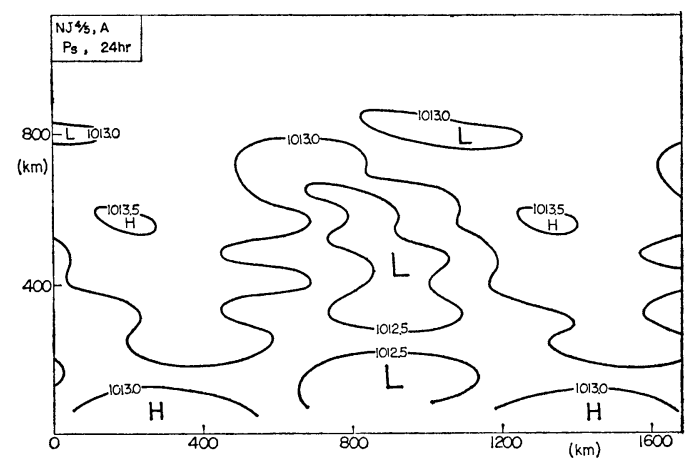

Fig. 7. Surface pressure pattern for Case $\mathrm{NJ} 4 / 5 \mathrm{~A}$ at $24 \mathrm{hrs}$.

this term is one order smaller than other terms even in Case $\mathrm{J} 1 / 2 \mathrm{~A}$. It is also noted that the sign of this term is positive. This is contrary to the result of quasi-geostrophic stability study (McIntyre, 1970; Stone, 1969), which indicates that the baroclinic disturbances in a jet supply their wave energy to the jet itself. It is mentioned that the jet profile of $\mathrm{J} 1 / 2 \mathrm{~A}$ is barotropically stable.

\subsection{Phase speed of disturbances}

All the disturbances move with the wind speed at the level between $700 \mathrm{mb}$ and $800 \mathrm{mb}$. The phase velocities are about $67 \mathrm{~km} / \mathrm{hr}$ (or $18 \mathrm{~m} / \mathrm{sec}$ ) for Case NJ $1 / 2 \mathrm{~A}, 37 \mathrm{~km} / \mathrm{hr}$ for Case NJ $2 \mathrm{~A}$ and $93 \mathrm{~km} / \mathrm{hr}$ for Case NJ 4/5 A.

\subsection{Surface pressure pattern}

Fig. 4 through Fig. 7 show the surface pressure patterns of the cases $\mathrm{NJ} 1 / 2 \mathrm{~A}, \mathrm{NJ} 2 \mathrm{~A}$ and $\mathrm{NJ} 4 /$ $5 \mathrm{~A}$. Since the pattern of $\mathrm{J} 1 / 2 \mathrm{~A}$ was similar to that of $\mathrm{NJ} 1 / 2 \mathrm{~A}$, it is not shown. Initial patterns of $\mathrm{NJ} 2 \mathrm{~A}$ and $\mathrm{NJ} 4 / 5 \mathrm{~A}$ are almost the same as 
(a)

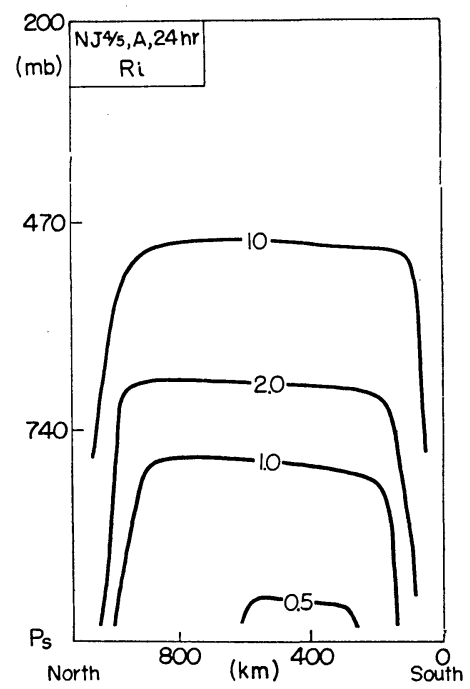

(c)

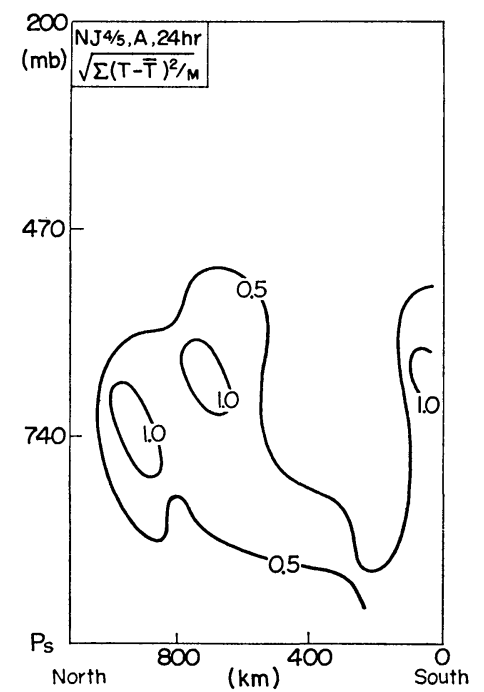

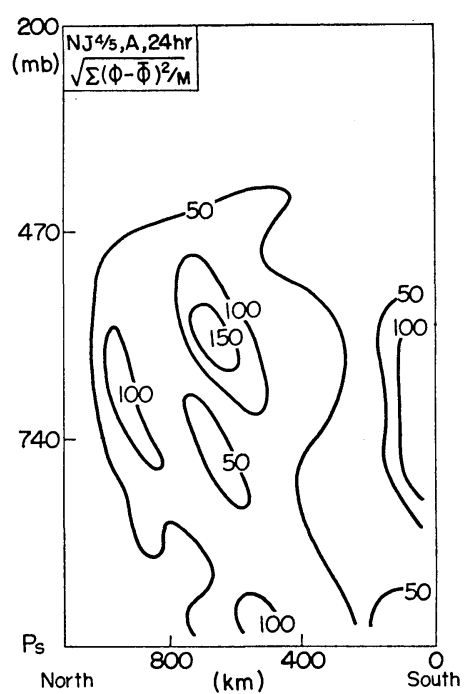

(b)

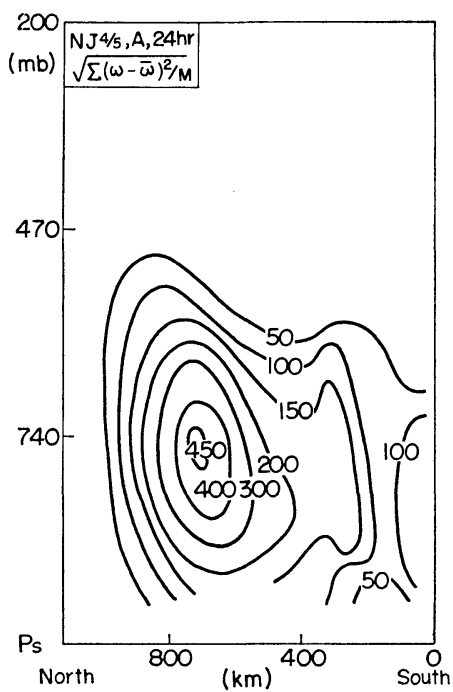

(d)

Fig. 8. (a) Meridional distribution of $R i$ calculated from the zonally averaged field for Case NJ 4/5 A at $24 \mathrm{hrs}$.

(b) Meridional distribution of standard deviation of geopotential (in unit $10^{-3} \mathrm{~km}^{2} / \mathrm{min}^{2}$ ).

(c) same as (b) but for temperature field (in unit deg.)

(d) same as (b) but for vertical $p$-velocity (in unit $10^{-3} \mathrm{mb} / \mathrm{min}$ )

that of NJ $1 / 2 \mathrm{~A}$ (Fig. 4). Differences in the surface pressure pattern between $\mathrm{NJ} 1 / 2 \mathrm{~A}$ and NJ $2 \mathrm{~A}$ are clearly seen in Fig. 5 and 6.

Ordinary baroclinic unstable waves prefer wide scales in the y-direction, though the most unstable scale in the $\mathrm{x}$-direction decreases to about

* This sense reverses when the vertical wind shear is' increased while the static stability is fixed.
$1,000 \mathrm{~km}$ with the decrease of $R i$ to unity*. Fig. 6 indicates that the disturbance in Case NJ $2 \mathrm{~A}$ have a characteristics of baroclinic waves, while Fig. 5 suggests a different type of disturbances from ordinary baroclinic waves.

Fig. 7 shows the surface pressure pattern of NJ $4 / 5 \mathrm{~A}$ at $24 \mathrm{hrs}$. In this case, no dry convective adjustment occured during the integration. 
(a)

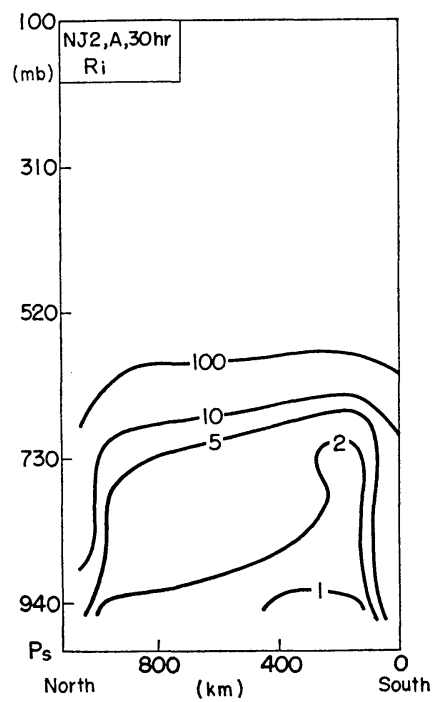

(c)

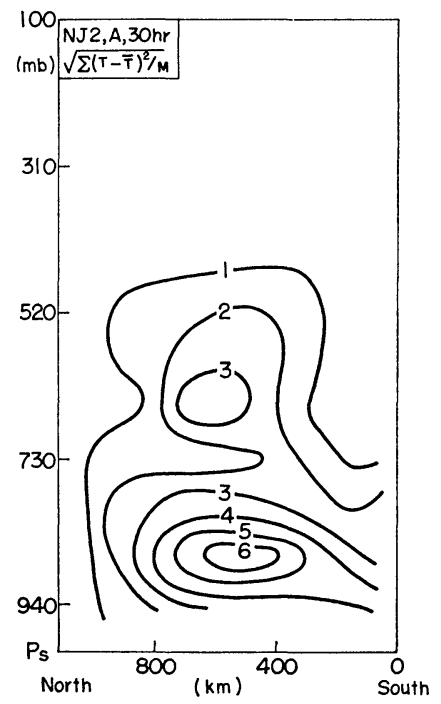

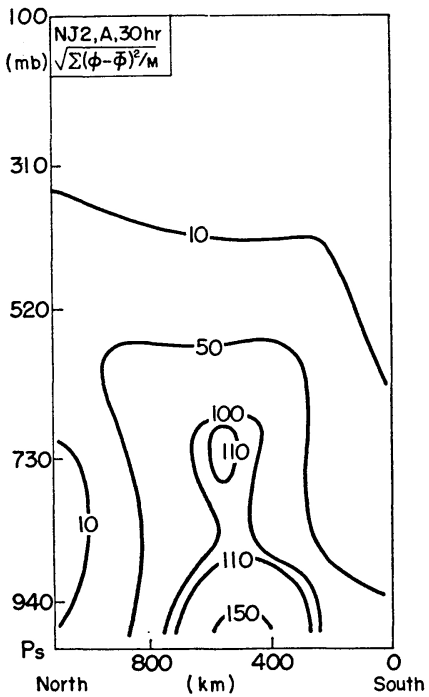

(b)

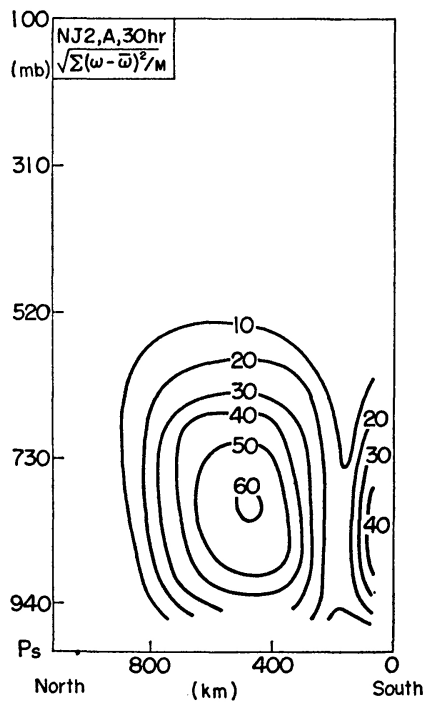

Fig. 9. Same as Fig. 8 but for Case NJ 2 A at 30 hrs.

It is noted that the disturbances are apt to subdivided in the y-direction. This tendency is also observed in Case NJ 1/2 A after ten and several hours of integration, when statically unstable region disappeared. The growth of such a disturbance just coincides with the result of stability study when $R i<1$.

The surface pressure patterns of NJ $2 \mathrm{~A}$ and NJ 1/2 A are well compared with Case $A$ and Case B of numerical models in Gambo (1970 b) respectively. Further comparison will be made in
Section 4.

3.4. Details of the disturbances of $N J 4 / 5 A$, $N J 2 A$ and $N J 1 / 2 A$

Fig. 8,9 and 10 show the meridional distribution of $R i$ calculated from the zonally averaged field, standard deviations from the zonally averaged value of temperature, geopotential and vertical $p$-velocity for the cases $\mathrm{NJ} 4 / 5 \mathrm{~A}$, NJ $2 \mathrm{~A}$ and $\mathrm{NJ} 1 / 2 \mathrm{~A}$ respectively.

Figs. 8 a-d are the results of Case NJ 4/5 A. 

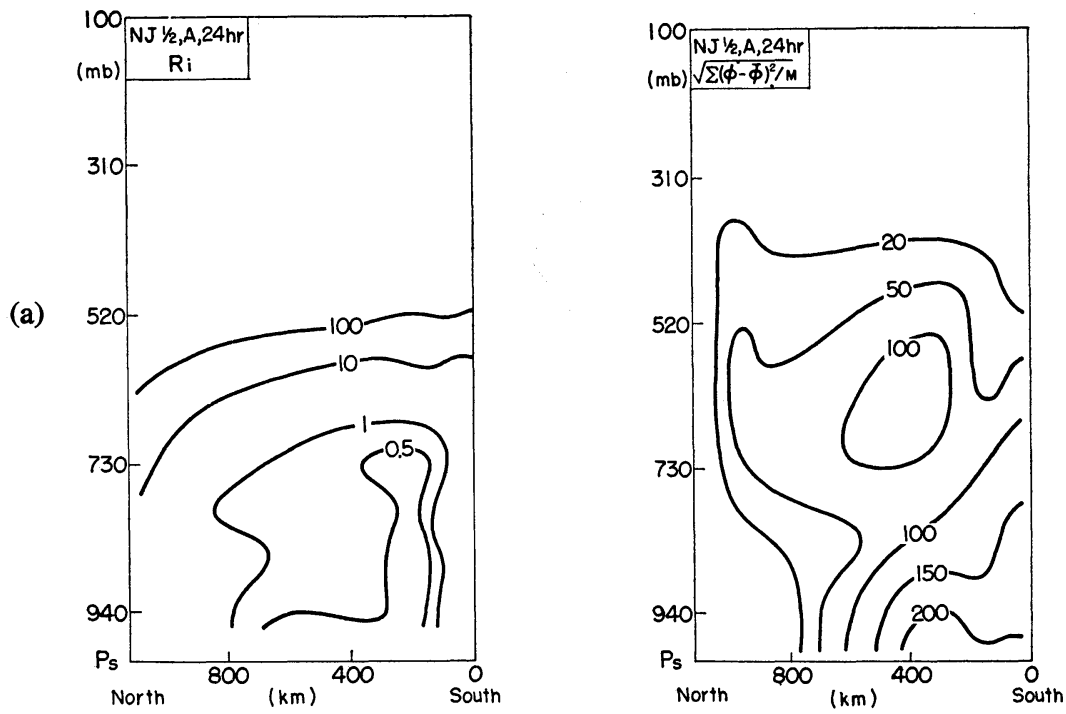

(b)
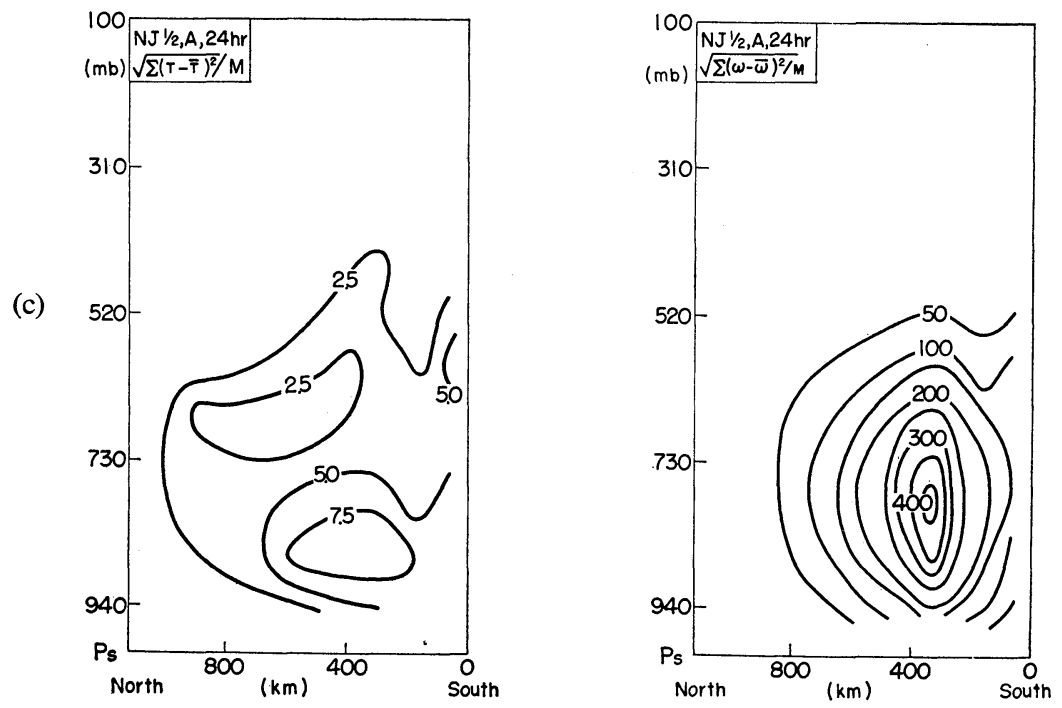

(d)

Fig. 10. Same as Fig. 8 but for Case NJ $1 / 2 \mathrm{~A}$ at 24 hrs.

The Richardson number is still less than unity (Fig. $8 \mathrm{a}$ ). It is known that purely symmetric instability exists when $R i<1$. It is characterized with the inclination angle of the disturbances in the meridional plane and the tendency toward smaller scale in the $y$-direction (Yanai and Tokioka, 1969). It is also known that symmetric type waves exist in the baroclinic model when $R i<1$. The amplitude distribution of geopotential in Case NJ 4/5 A (Fig. 8 b) shows the characteristics of symmetric type waves. Relatively small ampitude of temperature and large amplitude of $\omega$ compared with Case $\mathrm{NJ} 2 \mathrm{~A}$ are also noted.

Fig. 9 a shows a distribution of $R i$ in Case NJ 2 A. Representative value in the lower half domain is about 2.0. Standard deviations of geopotential and temperature (Figs. $9 \mathrm{~b}$ and c) indicate a typicl feature of ordinary barloclinic unstable waves, with two maxima, one at the surface and the other at about $700 \mathrm{mb}$ in this case. Zonal cross section of the disturbance of 


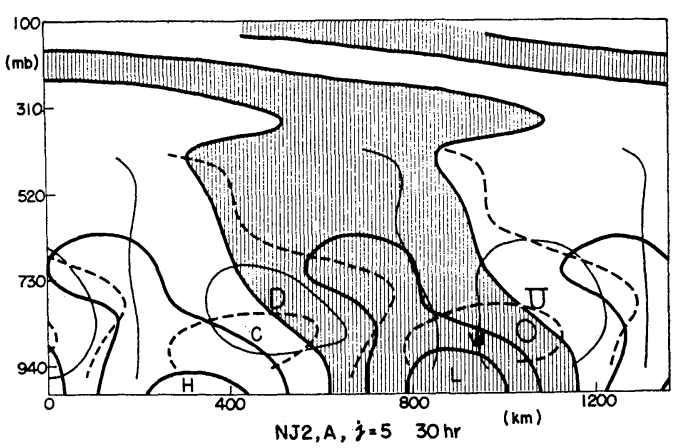

Fig. 11. Vertical cross section of disturbance field for Case $\mathrm{NJ} 2 \mathrm{~A}$ at $y=400 \mathrm{~km}, 30 \mathrm{hrs}$. Thick solid lines indicate geopotential (lower pressure area is shaded); dashed lines, temperature; thin solid lines, vertical $p$-velocity.
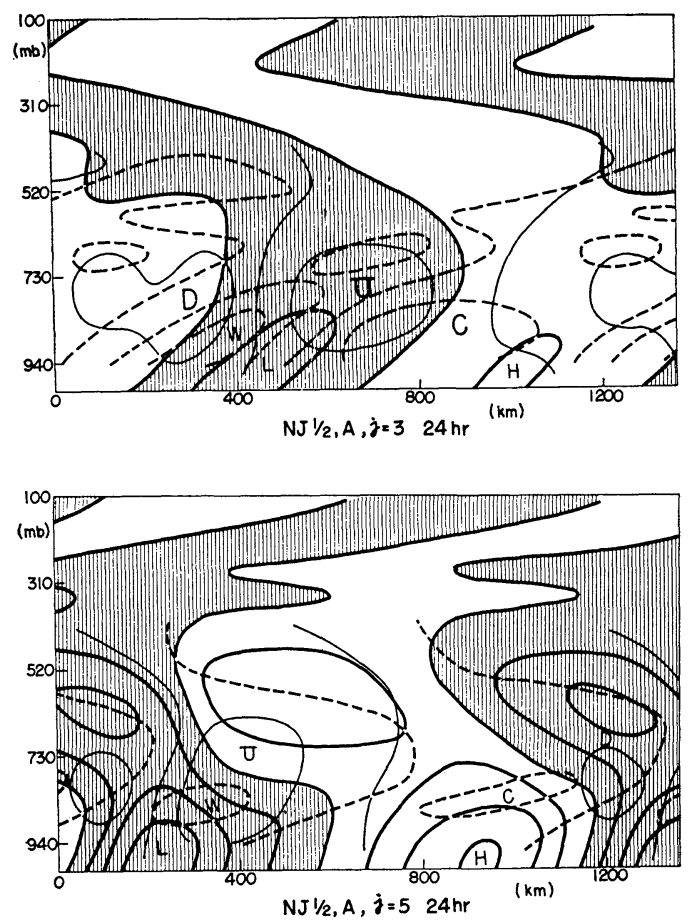

Fig. 12. Same as Fig. 11 but for Case $\mathrm{NJ} 1 / 2 \mathrm{~A}(\mathrm{a})$ at $y=240 \mathrm{~km}$, and (b) $y=400 \mathrm{~km}$.

Case NJ $2 \mathrm{~A}$ at $y=400 \mathrm{~km}$ (Fig. 11) and vertical distribution of energy conversion terms (Fig. 13) confirm more clearly the properties of baroclinic waves.

Finally we will study the structure of the disturbance in Case NJ 1/2 A. Statically unstable region in the initial field has disappeared at this

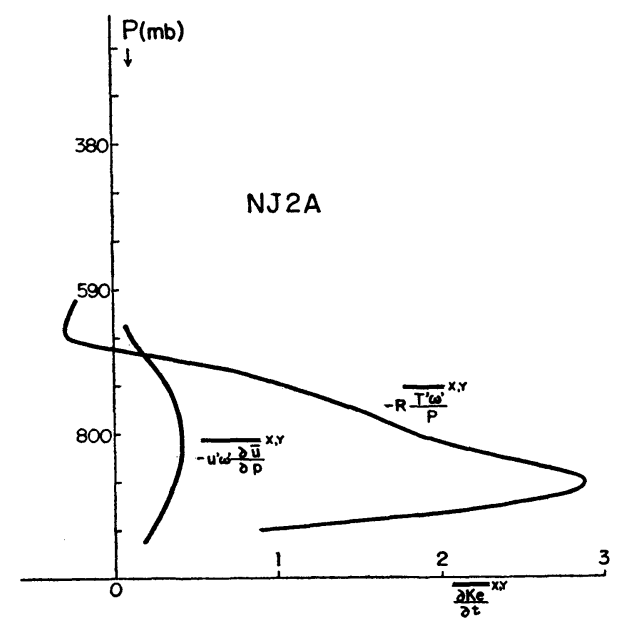

Fig. 13. Vertical distribution of energy conversion terms for Case $\mathrm{NJ} 2 \mathrm{~A}$ at $30 \mathrm{hrs}$ (in unit $8.96 \times 10 \mathrm{~km}^{4} /$ $\left.\min ^{3}\right)$.

time, and the averaged $R i$ is nearly equal to 0.5 in the lower part (Fig. 10 a). If we compare Figs. $10 \mathrm{~b}$ and $\mathrm{c}$ with those of Case NJ $2 \mathrm{~A}$ (i.e., Fig. $9 \mathrm{~b}$ and $\mathrm{c}$ ), we cannot find notable differences in these amplitude distributions. On the other hand, zonal cross sections of disturbance field (see Figs. $12 \mathrm{a}$ and b) show great differences from that of the ordinary baroclinic waves (compare with Fig. 11), reflecting the difference in the surface pressure pattern between Case NJ 1/2 A (Fig. 5). and Case NJ 2 A (Fig. 6). Fig. $12 \mathrm{a}$ and $12 \mathrm{~b}$ are the structures at $y=240 \mathrm{~km}$ and $y=400 \mathrm{~km}$ respectively. Eastward tilt of trough axis and temperature field in the lower level is notable. Relatively cold air exists on the eastward side of the surface low corresponding to the eastward tilt of the trough axis. Therefore $-\overline{\overline{T^{\prime} \omega^{\prime}}}$ correlation is negative in the lower level, while its correlation becomes positive in the upper part.

Fig. $10 \mathrm{~d}$ shows that the maximum p-velocity is about $0.4 \mathrm{mb} / \mathrm{min}$ (or $25 \mathrm{mb} / \mathrm{hr}$ ), which is one order larger than those associated with ordinary baroclinic waves (Fig. 9d). There are no observational evidences of such an order of $p$-velocity associated with medium-scale disturbances, however.

Fig. $14 \mathrm{a}$ shows the vertical distribution of energy conversion terms integrated in the whole horizontal plane, while Fig. $14 \mathrm{~b}$ shows the quantities integrated in the one third area from 


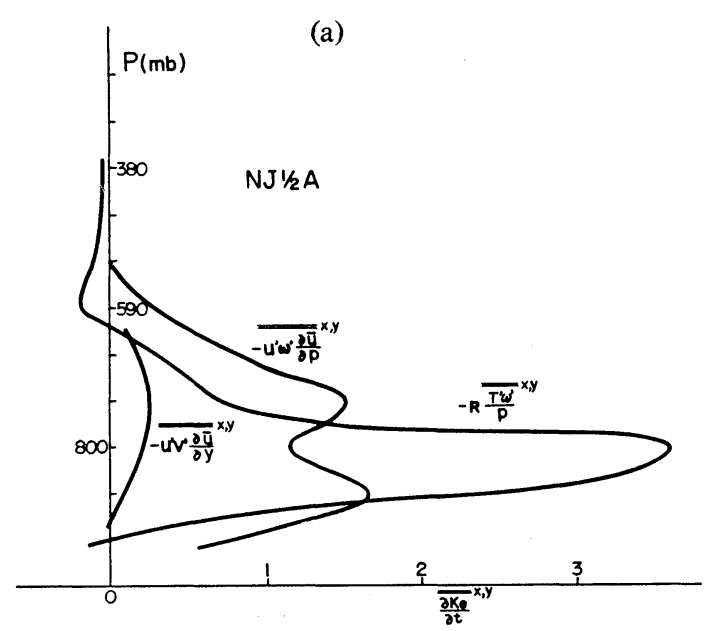

(b)

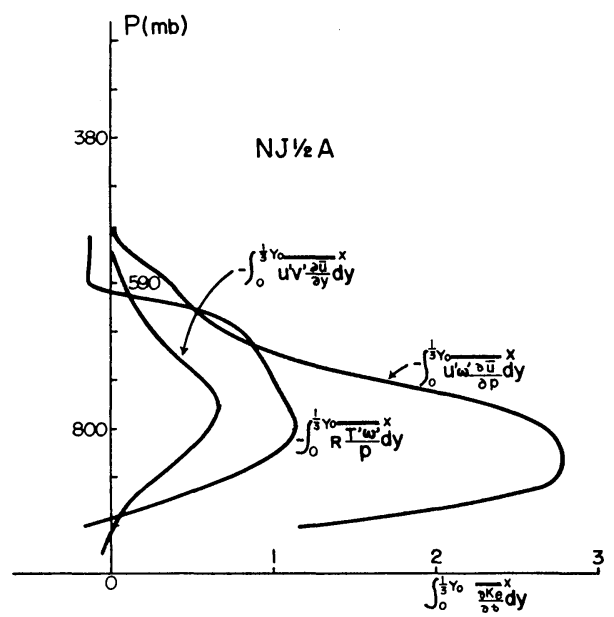

Fig. 14. Vertical distribution of energy convergion terms for Case NJ $1 / 2 \mathrm{~A}$ at $24 \mathrm{hrs}$. (a) integrated in the whole horizontal area (in unit $8.96 \times$ $125 \mathrm{~km}^{4} / \mathrm{min}^{3}$ ); ( b ) integrated in the $1 / 3$ domain from the south boundary where statically unstable domain existed initially (in unit $8.96 \times$ $\left.50 \mathrm{~km}^{4} / \mathrm{min}^{3}\right)$.

the south boundary, where unstable domain existed initially and rapid growth of disturbances was observed. Compared with Fig. 13, Figs. 14 a and $14 \mathrm{~b}$ show that the role of $-\overline{u^{\prime} \omega^{\prime} \frac{\partial \bar{u}}{\partial p}}$ in the lower levels is predominant for Case $\mathrm{NJ} 1 / 2 \mathrm{~A}$ corresponding to small $R i$. Fig. $14 \mathrm{~b}$ also indicates that the energy conversion from the basic kinetic energy to the disturbance kinetic energy through the vretical wind shear plays a dominant role on the growth of disturbances in the southern area.

\section{Discussions}

Five cases of numerical experiments were performed under the assumption of dry atmosphere. Several moist cases were also conducted but we failed in obtaining the growth of disturbances contrary to Gambo's experiment. One of the reasons may be due to the differences in the adjustment scheme. In our experiment the adjustment scheme similar to that of Manabe et. al (1965) was used. In Gambo's model, over-saturated water vapour does not immetiately fall out. Therefore the atmosphere can be wet enough until small disturbances organize their structure and attain some degrees of intensity of $p$-velocity. Another reason is that the wavelength in the $x$-direction could not be greater than $1,120 \mathrm{~km}$. Once the lower part of the atmosphere has become dry when the organization of disturbances has not yet been established and the intensity of $p$-velocity is still small to supply water vapour in the upper layer, the growth of organized medium-scale disturbances in the present cyclic model is suppressed. This is because the Richardson number becomes large when the atmosphere is not saturated, and in such a situation the preferred scale becomes a few thousand kilometers.

Despite of the unrealistic configurations of the initial zonal field, especially of the temperature field, the present numerical experiments will still give us some informations about the growth of medium-scale disturbances. First of all, the existence of three types of medium-scale disturbances was shown. Two of them, i.e., ordinary baroclinic waves (NJ $2 \mathrm{~A}$ ) and symmetric type waves (NJ 4/5 A) are expected from the linear stability analysis (Stone, 1966, 1970; Tokioka, $1970,1971)$. While, the remaining one (NJ $1 / 2 \mathrm{~A}$ ) does not correspond to any waves in the stability study.

By comparing the results of $\mathrm{NJ} 1 / 2 \mathrm{~A}$ with those of $\mathrm{NJ} 4 / 5 \mathrm{~A}$, we can say that the characteristic feature of the disturbances shown in Fig. 5,10 and 12 is utterly due to the effect of heat redistribution through the dry convective adjustment, which is the most important difference 
between the two cases. (Since convective motions are filtered in the models by use of the adjustment scheme, the presence of statically unstable domain plays an effective role only through the convective adjustment in that area. Difference in the magnitude of $p$-velocity is not appreciable between Case NJ $1 / 2 \mathrm{~A}$ and Case NJ 4/5 A).

As is already stated in Section 3.2, there are resemblances in the surface pressure pattern between NJ 1/2 A and Case B, and between NJ $2 \mathrm{~A}$ and Case A. There are, however, several differences between the present model and Gambo's model. The differences are;

i) Present model deals with the dry atmosphere while Gambo's model treats the moist atmosphere.

ii ) NJ 1/2 A and NJ $2 \mathrm{~A}$ assume no jet profile, while Case A and $\mathrm{B}$ assume jet profile.

iii) NJ 1/2 A initially has statically unstable region.

On the other hand resemblances are summarized as follows;

i) Heat redistribution due to convective adjustment exists in both $\mathrm{NJ} 1 / 2 \mathrm{~A}$ and Case B.

ii) Effective Richardson number is of the same order between NJ 1/2 A and Case A.

As the details of the characteristic feature of the disturbances are not stated in Gambo (1970b) except the surface pressure pattern, we have no other means to compare the results directly. Concerning the difference ii), however, we may say the jet profile in Case $\mathbf{A}$ and Case $\mathbf{B}$ will have a minor role in the development of disturbances, because the jet profile of them is the same as that of Case J1/2 A, and Fig. 3 shows no appreciable differences between jet case and no jet case.

In Case $\mathrm{B}$, it is expected from the process of convective adjustment used by Gambo that convective adjustment lasted for long periods although moisture was not supplied except at initial time. There is a difference between a dry convective adjustment and a moist convective adjustment in the effect of heating. Net heating does not exist in the present dry convective adjustment. The results of Case NJ 1/2 A, however, suggest that even in the absence of net heating medium-scale disturbances are greatly influenced by the effect of heat redistribution. Therefore, if the redistribution of heat is impor- tant for the organization of the disturbance in Case $\mathrm{B}$, the characteristics of the disturbances in Case $\mathrm{B}$ are expected to be similar to those in Case NJ 1/2 A despite of some differences between the models.

Recently, present author studied a stability property of baroclinic fluids at small $R i$ with inclusion of convective heating effects. From that study, a growth rate peak corresponding to medium-scale disturbances which are different from ordinary baroclinic waves was obtained. They are similar to the disturbances of Case NJ $1 / 2 \mathrm{~A}$ in the structure. On the other hand, Yoshizumi* analyzed a structure of medium-scale disturbances in the "Baiu front". His results also have a resemblance to the results of the present numerical experiment $\mathrm{NJ} 1 / 2 \mathrm{~A}$.

The similarity in the structure among Case $\mathrm{NJ} 1 / 2 \mathrm{~A}$, the results of stability study mentioned above, the results of Yoshizumi's analysis and probably Case B, suggests an existence of common effect among them on the development of these medium-scale disturbances. The present numerical study implies an important role of heat redistribution in such medium-scale waves, but further study will be needed to this problem.

\section{Summary}

From the numerical experiments, the followings are summarized;

i) In Case NJ 1/2 A, medium-scale disturbances which are different from ordinary baroclinic waves were obtained. Redistribution of heat due to dry convective adjustment is the main cause of the development of this disturbances. Trough axis and temperature field inclines eastward in the lower part and rather cold air exists on the eastward side of the surface low pressure area corresponding to the inclination of the trough axis. Therefore the circulation is indirect sense near the surface. Energy conversion from the zonal kinetic energy through the vertical wind shear is of the comparable order with that from potential energy.

ii) When there are no adjustment process and $R i<1$, small scale disturbances in the meridional direction (symmetric type instability) prevailed in accordance with the

\footnotetext{
* Reported at the annual meeting of the Meteoro-
} logical Society of Japan, May 1971. 
results of linear stability analysis.

iii) When $R i \sim 2$, ordinary baroclinic unstable waves developed.

iv) The effect of the jet profile has a minor role in the present calculation on the growth of disturbances.

v) The surface pressure pattern of Case NJ 1/2 A resembles that of Case B obtained by Gambo (1970 b).

\section{Acknowledgements}

The author wishes to thank Prof. Gambo of Tokyo Univ. for his encouragement throughout this work. He is also indebted to Dr. Takashi Nitta of Japan Meteorological Agency, who gave him accomodation in many respects throughout the accomplishment of numerical calculation. Thanks are extended to Dr. I. Hirota for carefully reading the manuscript, Mrs. $H$. Shinoda for drafting and Miss K. Nishida for typing.

\section{Refefences}

Eady, E.T., 1949; Long waves and cyclone waves. Tellus, 1, 33-52.

Gambo, K., 1970 a; The characteristic feature of medium-scale disturbances in the atmosphere I. $J$. Meteor. Soc. Japan, 48, 173-184. $1970 \mathrm{~b}$; The characteristic feature of medium scale disturbances in the atmosphere II. J. Meteor. Soc. Japan, 48, 315-330.

Manabe, S., J. Smagorinsky and R.F. Strickler, 1965; Simulated climatology of a general circulation model with a hydrologic cycle.. Mon. Wea. Rev., 93, 769-787.

Matsumoto, S., S. Yoshizumi and M. Takeuchi, 1970; On the structure of the "Baiu front" and the associated intermediate-scale disturbances in the lower atmosphere. J. Meteor. Soc. Japan, 48, 479-491.

K. Ninomiya and S. Yoshizumi, 1971; Characteristic features of "Baiu" front associated with heavy rainfall. J. Meteor. Soc. Japan, 49, 267-281.

Matsuno, T., 1966; Numerical integrations of the primitive equations by a simulated backward difference method. J. Meteor. Soc. Japan, 44, 76-84.

McIntyre, M.E., 1970; On the non-separable baroclinic parallel flow instability. J. Fluid Mech., 40, 273306.

Stone, P.H., 1966; On non-geostrophic baroclinic stability. J. Atmos. Sci., 27, 390-400.

, 1969; The meridional structure of baroclinic waves. J. Atmos. Sci., 26, 376-389.

, 1970; On non-geostrophic baroclinic stability: Part II. J. Atmos. Sci., 27, 721-726.

Tokioka, T., 1970; Non-geostrophic and non-hydrostatic stability of a baroclinic fluid. J. Meteor. Soc. Japan, 48, 503-520.

1971; Supplement to non-geostrophic and non-hydrostatic stability of a baroclinic fluid and medium-scale disturbances on the fronts. $J$. Meteor. Soc. Japan, 49, 129-132.

Yanai, M., and T. Tokioka, 1969; Axially symmetric meridional motions in the baroclinic circular vortex: a numerical experiment. J. Meteor. Soc. Japan, 47, 183-198.

\title{
ドライモデルによる中間規模擾乱の数值実験
}

\author{
時岡 達 志 \\ 気象研究所
}

チャンネル流中でドライモデルを使って中間規模擾乱の数值実験を行なった。 その結果, 三種類の型の擾乱の発達 が得られた。まず第一は，初期の基本場のリチャードソン数 (Ri) がおよそ 2.0 の時で，この場合は普通の傾圧不 安定波が発達した. 第 2 は初期の $\mathrm{Ri}$ が 0.4 の時で, シンメトリック型の擾乱が生じ，南北方向のスケールが時間 と共に小さくなる傾向がみられた。第 3 は初期場の中に成層不安定の領域が若干ある場合で, この時は普通の傾圧波 とは異った構造をもった擾乱が発達した。この波動のトラフは下層で東に傾き，それに対応してその前面に低温域が 存在して間接循環となっている。しかし上部では強い直接循環となっている.下層では基本場の運動エネルギーが垂 直シアーを通して擾乱に与えられている。この擾乱の組織化には，対流調節による熱の再配分が重要な役割を果して いる. この場合の地表気圧図は, 岸保 $(1970$ b) の Case B と似ている. 